\title{
Oclusão Aórtica Aguda: Uma Emergência Rara
}

\section{Acute Aortic Occlusion: A Rare Emergency}

Diogo Moderno Costa ${ }^{1 *}$, Teresa Matos Queirós², Ana Sofia Tavares ${ }^{3}$

PALAVRAS-CHAVE: Arteriopatias Oclusivas; Trombectomia; Tromboembolismo

KEYWORDS: Arterial Occlusive Diseases; Thrombectomy; Thromboembolism

Homem de 72 anos, fumador, com diabetes tipo 2, hipertensão arterial e enfarte agudo do miocárdio com cirurgia de revascularização, suspendeu medicação há 3 anos por iniciativa própria. Inicia quadro de dor súbita no terço distal da perna esquerda com pé frio e sem pulsos pedioso e tibial posterior. Hemodinamicamente estável é encaminhado ao serviço de urgência por suspeita de isquemia aguda, chegando sem pulsos femorais bilateralmente. Realizou angiografia por tomografia computorizada (angio-TC), diagnosticando-se uma oclusão aórti- ca aguda extensa (Fig. 1). Inicia paresia do pé esquerdo e é submetido a tromboembolectomia aorto-ilíaca distal bilateral por via femoral com recuperação total (Fig. 2).

A oclusão aórtica aguda é rara e tem elevada morbi-mortalidade. ${ }^{1}$ As causas mais comuns são grandes êmbolos que ocluem a bifurcação da aorta, trombose in situ de uma aorta aterosclerótica e oclusão de reconstruções cirúrgicas prévias. ${ }^{2}$ 


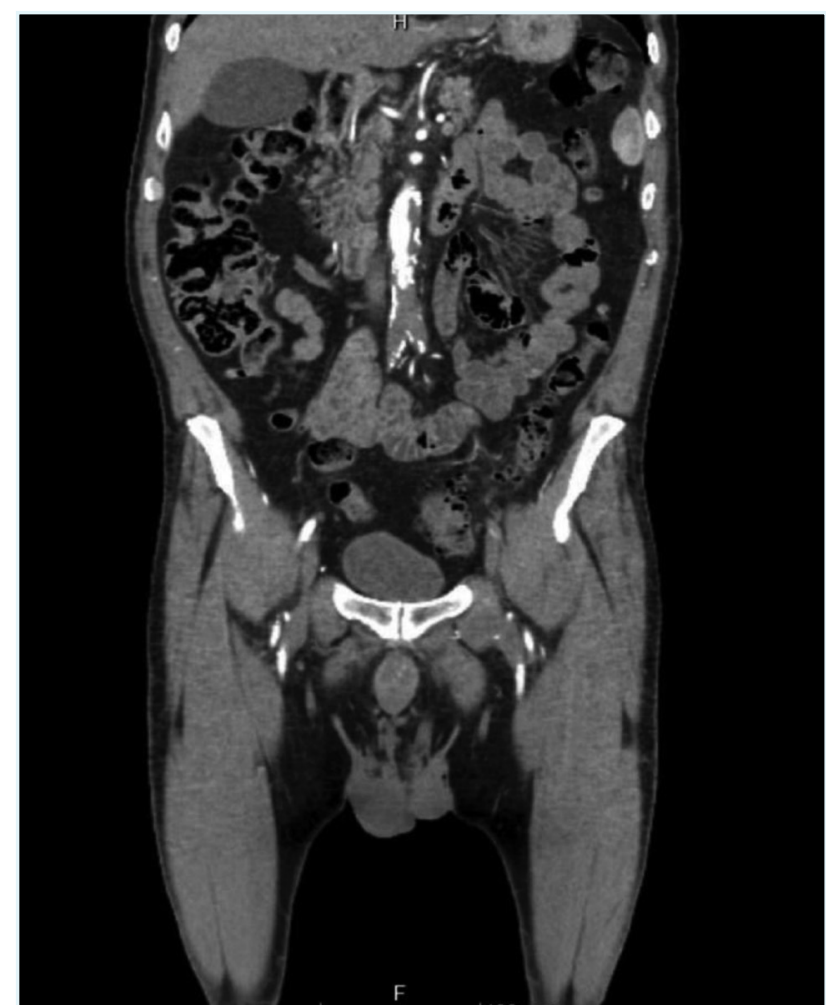

FIGURA 1. Angio-TC mostrando trombo endoluminal com início na aorta infrarrenal e extensão distal para as artérias ilíacas.

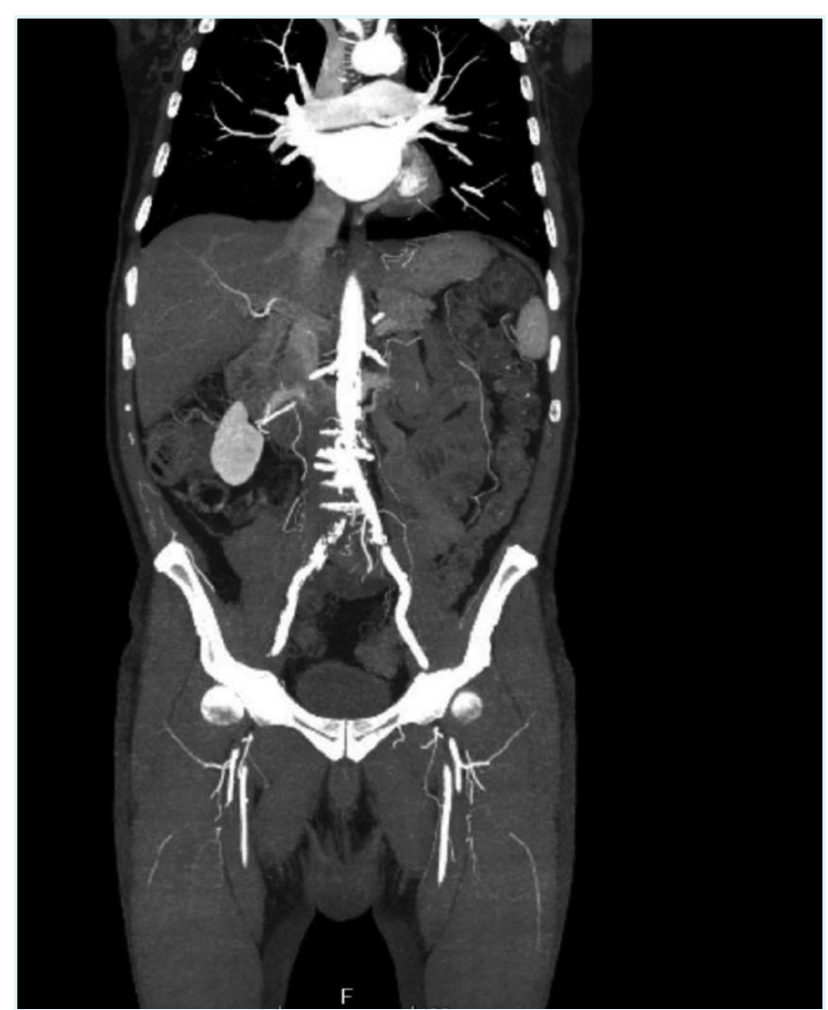

FIGURA 2. Angio-TC de controlo mostrando a aorta abdominal preservada e permeável, revelando sucesso terapêutico.

\section{RESPONSABILIDADES ÉTICAS}

CONFLITOS DE INTERESSE: Os autores declaram a inexistência de conflitos de interesse na realização do presente trabalho.

FONTES DE FINANCIAMENTO: Não existiram fontes externas de financiamento para a realização deste artigo.

CONFIDENCIALIDADE DOS DADOS: Os autores declaram ter seguido os protocolos da sua instituição acerca da publicação dos dados de doentes.

CONSENTIMENTO: Consentimento do doente para publicação obtido.

PROVENIÊNCIA E REVISÃO POR PARES: Não comissionado; revisão externa por pares.

\section{ETHICAL DISCLOSURES}

CONFLICTS OF INTEREST: The authors have no conflicts of interest to declare.

FINANCING SUPPORT: This work has not received any contribution, grant or scholarship.

CONFIDENTIALITY OF DATA: The authors declare that they have followed the protocols of their work center on the publication of data from patients.

PATIENT CONSENT: Consent for publication was obtained.

PROVENANCE AND PEER REVIEW: Not commissioned; externally peer reviewed.

\section{REFERÊNCIAS}

1. Singh D, Pinjala R, Divakar B. Acute aortic occlusion: time to awake, be aware and act. Internet J Surg. 2006;9:1-6.

2. Olivia G, Anders W, MartinB. Acute Aortic Occlusion: Nationwide Cohort Study. Circulation. 2019;139:292-4. doi:10.1161/CIRCULATIONAHA.118.036420. 